\title{
Associations between matrix metalloproteinase gene polymorphisms and the development of cerebral infarction
}

\author{
J.H.Zhao ${ }^{1,2}$, Y.M.Xu', H.X.Xing ${ }^{2}$, L.L.Su' ${ }^{2}$, S.B. Tao ${ }^{2}$, X.J. Tian ${ }^{2}$, H.Q. Yan ${ }^{2}$ and S.B. Ji ${ }^{2}$ \\ ${ }^{1}$ The First Affiliated Hospital of Zhengzhou University, Zhengzhou, Henan, China \\ ${ }^{2}$ Department of Neurology, \\ The First Affiliated Hospital of Xinxiang Medical University, Weihui, China \\ Corresponding author: Y.M. Xu \\ E-mail: jisibeib@126.com \\ Genet. Mol. Res. 14 (4): 19418-19424 (2015) \\ Received August 11, 2015 \\ Accepted October 18, 2015 \\ Published December 30, 2015 \\ DOI http://dx.doi.org/10.4238/2015.December.30.3
}

\begin{abstract}
The aim of this study was to investigate the association between MMP3 rs3025058 and MMP9 rs3918242 polymorphisms and the development of ischemic stroke in a Chinese population. Between May 2013 and January 2015, 335 patients with ischemic stroke and 335 health control subjects were enrolled in this study. The MMP3 rs3025058 and MMP9 rs3918242 polymorphisms were analyzed using polymerase chain reaction coupled with restriction fragment length polymorphism. By multivariate logistic regression analysis, the CC genotype of MMP9 rs3918242 was shown to be associated with a significantly increased risk of ischemic stroke when compared with the TT genotype [OR $(95 \% \mathrm{Cl})=5.47$ (2.64-12.38)]. The TC+CC genotype of MMP9 rs3918242 was furthermore found to be associated with an elevated risk of ischemic stroke in higher BMI individuals [OR $(95 \% \mathrm{Cl})=1.81(1.03-3.22)]$. The findings of this study suggest that the MMP9 rs3918242 polymorphism is associated with an elevated risk of ischemic stroke and that this gene polymorphism interacts with $\mathrm{BMI}$ in the risk of ischemic stroke.
\end{abstract}

Key words: Matrix metalloproteinases; Polymorphism; Cerebral infarction 


\section{INTRODUCTION}

Ischemic stroke is a complex and devastating vascular disease that has become one of the leading causes of disability and mortality worldwide. The etiology of ischemic stroke is not well understood; however, ischemic stroke is known to be caused by a large array of biological and lifestyle factors including hypertension, diabetes, drinking, and smoking (Goldstein et al., 2011). Moreover, genetic factors are involved in the development of ischemic stroke since not all individuals would develop ischemic stroke.

Increasing evidence has reported that inflammation has an important role in ischemic stroke susceptibility. Matrix metalloproteinases (MMPs) are an inflammatory mediator that belong to a family of zinc-dependent proteolytic enzymes, and are involved in degrading the extracellular matrix (ECM). The MMPs function in the development of atherosclerosis through activation of migration and proliferation of smooth muscle cells and inducing the artherosclerotic plaques (Galis and Khatri, 2002; Katakami et al., 2010). Previous studies have reported that alteration of MMP activity are observed in the cardiovascular and cerebrovascular diseases (Siefert and Sarkar, 2012; Chen et al., 2013).

Expression of MMP3, and MMP9 has previously been reported to be associated with risk of ischemic stroke (Moniche et al., 2014; Zhang et al., 2015). Only little research has, however, been done on the role of MMP3 and MMP9 polymorphisms in the susceptibility to ischemic stroke, and the results of such research have been inconclusive (Fatar et al., 2008; Kaplan et al., 2008). In this study, we therefore assessed the association between MMP3 rs3025058 and MMP9 rs3918242 polymorphisms and the susceptibility of ischemic stroke in a Chinese population.

\section{MATERIAL AND METHODS}

\section{Study participants}

This study was a case-control study in which a total of 335 patients from the First Affiliated Hospital of Xinxiang Medical University with proved ischemic stroke were enrolled between May 2013 and January 2015. Patients were confirmed with ischemic stroke by computed tomography (CT) or magnetic resonance imaging (MRI) based on the diagnostic criteria of ischemic stroke from World Health Organization. Patients who had intracranial hemorrhage, brain tumors, and brain trauma were excluded from the present study.

Three hundred and thirty-five healthy control subjects were randomly selected from the outpatients who visited the hospital for health check-ups. The control subjects were age- and gender-matched with the patients. Controls were free of ischemic stroke.

The clinical and demographic characteristics of patients with ischemic stroke and control subjects were interviewed using a standardized questionnaire, which included questions regarding their socio-demographic characteristics, including age, gender, body mass index, tobacco smoking, and alcohol drinking. Detailed clinical data, including hypertension, diabetes mellitus, total cholesterol, triglyceraldehydes, high-density lipoprotein and low-density lipoprotein, of patients with ischemic stroke were collected from their medical records.

Blood samples and signed written informed consents were obtained from each ischemic stroke patient and control subject prior to enrollment in the study. The study was approved by the Ethics Committee of the First Affiliated Hospital of Xinxiang Medical University. 


\section{Genotyping assays}

The blood samples (5 mL) were collected in EDTA-containing tubes and stored at $-20^{\circ} \mathrm{C}$ until use. Genomic DNA was isolated from the blood sample using the TIANamp Blood DNA Kit (Tiangen, Beijing, China). The MMP3 rs3025058 and MMP9 rs3918242 polymorphisms were done by polymerase chain reaction (PCR) coupled with restriction fragment length polymorphism (RFLP). The forward and reverse primers, respectively, were 5'-ACGTTGGATCATATCTCCGG-3' and 5'-ACGTTCCATGCTATCTCCAT-3' for MMP3 rs3025058; and 5'-CCGTGGCACACTATGCCCGG-3' and 5'-CTTCCTAGCCAGGGCCGATC-3' for MMP9 rs3918242. The PCRs were set as follows: $95^{\circ} \mathrm{C}$ for $5 \mathrm{~min}$ for initial denaturation, and 30 cycles of denaturation at $95^{\circ} \mathrm{C}$ for $30 \mathrm{~s}$, annealing at $59^{\circ} \mathrm{C}$ for $45 \mathrm{~s}$, extension at $72^{\circ} \mathrm{C}$ for 30 $\mathrm{s}$, and a final extension at $72^{\circ} \mathrm{C}$ for $5 \mathrm{~min}$. PCR products of the MMP3 rs3025058 and MMP9 rs3918242 were digested by $P f I F 1$ and Sphl restriction enzymes, and resulting fragments were separated on a $2 \%$ agarose gel. The fragment sizes were $187 \mathrm{bp}$ for the $6 \mathrm{~A}$ allele of rs3025058, and 157 and $30 \mathrm{bp}$ for the $5 \mathrm{~A}$ allele. The fragment sizes were $435 \mathrm{bp}$ for the $\mathrm{C}$ allele of rs3918242, and 247 and $188 \mathrm{bp}$ for the $\mathrm{T}$ allele.

\section{Statistical analysis}

All statistical analysis was done using the SPSS software for Windows version 20.0 (SPSS Inc., Chicago, IL, USA). Statistically significant differences between cases and controls for demographic and clinical data were compared by the independent sample $t$-test and the $\chi^{2}$ test. Fisher exact tests were taken to analyze whether MMP3 rs3025058 and MMP9 rs3918242 genotypes were in line with the Hardy-Weinberg equilibrium in controls. The associations between the MMP3 rs3025058 and MMP9 rs3918242 polymorphisms and ischemic stroke risk were determined by estimating the odds ratio $(\mathrm{OR})$ and $95 \%$ confidence interval $(95 \% \mathrm{Cl})$ by logistic regression. The major homozygous genotype of the MMP3 rs3025058 and MMP9 rs3918242 was used as a reference. Differences with $\mathrm{P}$ values $<0.05$ were considered to be statistically significant.

\section{RESULTS}

The mean ages of patients with ischemic stroke and of control subjects were $63.65 \pm 9.40$ and $64.45 \pm 9.15$ years, respectively. Both the ischemic stroke group and the healthy control group consisted of 141 females and 194 males. No significant difference was found between the patients and control subjects in terms of gender and age. Compared with the control subjects, the patients with ischemic stroke were more likely to have higher BMI $(t=5.09, \mathrm{P}<0.001)$, hypertension $\left(\chi^{2}=\right.$ 8.20, $\mathrm{P}=0.004)$, total cholesterol $(t=41.49, \mathrm{P}<0.001)$, triglyceraldehydes $(t=4.29, \mathrm{P}<0.001)$, high-density lipoprotein $(t=68.90, \mathrm{P}<0.001)$ and low-density lipoprotein $(t=151.12, \mathrm{P}<0.001)$, and diabetes mellitus $\left(\chi^{2}=29.99, P<0.001\right)$, and were more likely to smoke tobacco $\left(\chi^{2}=4.90, P\right.$ $<0.001)$ and drink alcohol $\left(\chi^{2}=4.07, \mathrm{P}<0.001\right)$ (Table 1).

The genotype distributions of MMP3 rs3025058 and MMP9 rs3918242 are shown in Table 2. The observed genotype frequencies of MMP9 rs3918242 in controls were in line with the Hardy-Weinberg equilibrium ( $P$ for HWE $=0.08$ ), while genotype distributions of MMP3 rs3025058 were not $(P<0.001)$. By the chi-squire test, a significant difference was observed in the genotype 
frequencies of MMP9 rs3918242 between the ischemic stroke group and the control group $\left(\chi^{2}=\right.$ 27.27, $P<0.05$ ), while no significant difference was found in the genotype frequencies of MMP3 rs3025058 $\left(\chi^{2}=0.79, P>0.05\right)$. By multivariate logistic regression analysis, the presence of the CC genotype of MMP9 rs3918242 was correlated with a significantly increased risk of ischemic stroke compared to the TT genotype, with an OR $(95 \% \mathrm{Cl})$ of $5.47(2.64-12.38)$.

\begin{tabular}{|c|c|c|c|c|c|c|}
\hline Variables & Patients $(\mathrm{N}=335)$ & $\%$ & Controls $(\mathrm{N}=335)$ & $\%$ & $\chi^{2}$ or $t$-test & $P$ value \\
\hline Age [years (mean \pm SD)] & $63.65 \pm 9.40$ & & $64.45 \pm 9.15$ & & 1.12 & 0.13 \\
\hline$\leq 60$ & 156 & 46.57 & 158 & 47.16 & & \\
\hline$>60$ & 179 & 53.43 & 177 & 52.84 & 0.02 & 0.88 \\
\hline \multicolumn{7}{|l|}{ Gender } \\
\hline Females & 141 & 42.09 & 141 & 42.09 & & \\
\hline Males & 194 & 57.91 & 194 & 57.91 & 0.00 & 1.00 \\
\hline Body mass index $\left(\mathrm{kg} / \mathrm{m}^{2}\right)$ & $24.8 \pm 3.2$ & & $23.6 \pm 2.9$ & & 5.09 & $<0.001$ \\
\hline \multicolumn{7}{|l|}{ Hypertension } \\
\hline No & 196 & 58.51 & 159 & 47.46 & & \\
\hline Yes & 139 & 41.49 & 176 & 52.54 & 8.20 & 0.004 \\
\hline \multicolumn{7}{|l|}{ Diabetes mellitus } \\
\hline No & 249 & 74.33 & 303 & 90.45 & & \\
\hline Yes & 86 & 25.67 & 32 & 9.55 & 29.99 & $<0.001$ \\
\hline \multicolumn{7}{|l|}{ Tobacco smoking } \\
\hline Never & 189 & 56.42 & 217 & 64.78 & & \\
\hline Yes & 146 & 43.58 & 118 & 35.22 & 4.90 & 0.03 \\
\hline \multicolumn{7}{|l|}{ Alcohol intake } \\
\hline Never & 170 & 50.75 & 196 & 58.51 & & \\
\hline Yes & 165 & 49.25 & 139 & 41.49 & 4.07 & 0.04 \\
\hline Total cholesterol (mg/dL) & $227.30 \pm 22.64$ & & $162.50 \pm 17.45$ & & 41.49 & $<0.001$ \\
\hline Triglyceraldehydes (mg/dL) & $106.42 \pm 26.16$ & & $97.32 \pm 28.66$ & & 4.29 & $<0.001$ \\
\hline High-density lipoprotein (mg/dL) & $176.35 \pm 10.67$ & & $104.30 \pm 15.89$ & & 68.90 & $<0.001$ \\
\hline Low-density lipoprotein (mg/dL) & $179.70 \pm 10.61$ & & $87.40 \pm 3.52$ & & 151.12 & $<0.001$ \\
\hline
\end{tabular}

Table 2. Associations between MMP polymorphisms (MMP3 rs3025058 and MMP9 rs3918242) and ischemic stroke risk.

\begin{tabular}{|c|c|c|c|c|c|c|c|c|c|}
\hline Gene & $\begin{array}{l}\text { Patients } \\
(\mathrm{N}=335)\end{array}$ & $\%$ & $\begin{array}{l}\text { Controls } \\
(\mathrm{N}=335)\end{array}$ & $\%$ & $\chi^{2}$ test & $P$ value & $\begin{array}{l}\text { P for Hardy-Weinberg } \\
\text { equilibrium }\end{array}$ & OR $(95 \% \mathrm{Cl})^{1}$ & $P$ value \\
\hline \multicolumn{10}{|c|}{ MMP3 rs3025058 } \\
\hline $5 \mathrm{~A} / 5 \mathrm{~A}$ & 232 & 69.25 & 243 & 72.54 & & & & 1.0 (Ref.) & - \\
\hline $5 \mathrm{~A} / 6 \mathrm{~A}$ & 53 & 15.82 & 49 & 14.63 & & & & $1.13(0.72-1.78)$ & 0.57 \\
\hline $6 \mathrm{~A} / 6 \mathrm{~A}$ & 50 & 14.93 & 44 & 13.13 & 0.79 & 0.67 & $<0.001$ & $1.19(0.75-1.90)$ & 0.44 \\
\hline \multicolumn{10}{|c|}{ MMP9 rs3918242 } \\
\hline TT & 223 & 66.57 & 254 & 75.82 & & & & 1.0 (Ref.) & - \\
\hline TC & 64 & 19.10 & 71 & 21.19 & & & & $1.03(0.69-1.53)$ & 0.89 \\
\hline $\mathrm{CC}$ & 48 & 14.33 & 10 & 2.99 & 27.27 & $<0.001$ & 0.08 & $5.47(2.64-12.38)$ & $<0.001$ \\
\hline
\end{tabular}

${ }^{1}$ Adjusted for body mass index, hypertension, diabetes mellitus, tobacco smoking, alcohol drinking, total cholesterol, triglyceraldehydes, high-density lipoprotein, and low-density lipoprotein.

Further analysis was carried out for the association between MMP9 rs3918242 and ischemic stroke risk stratified by demographic characteristics including BMI, hypertension, diabetes mellitus, tobacco smoking, and alcohol intake (Table 3). By logistic regression analysis, the TC+CC genotype of MMP9 rs3918242 was observed to be correlated with an elevated risk of ischemic stroke in higher BMI individuals, with an OR $(95 \% \mathrm{Cl})$ of $1.81(1.03-3.22)$. 
Table 3. Association between MMP9 rs3918242 and risk of ischemic stroke stratified by demographic characteristics.

\begin{tabular}{|c|c|c|c|c|c|c|}
\hline \multirow[t]{2}{*}{ Variables } & \multicolumn{2}{|c|}{ Case } & \multicolumn{2}{|c|}{ Control } & \multirow[t]{2}{*}{ OR $(95 \% \mathrm{Cl})$} & \multirow[t]{2}{*}{$P$ value } \\
\hline & TT & $\mathrm{TC}+\mathrm{CC}$ & TT & $\mathrm{TC}+\mathrm{CC}$ & & \\
\hline \multicolumn{7}{|c|}{ Body mass index } \\
\hline$\leq 24$ & 92 & 49 & 160 & 56 & $1.52(0.93-2.48)$ & 0.07 \\
\hline$>24$ & 131 & 63 & 94 & 25 & $1.81(1.03-3.22)$ & 0.03 \\
\hline \multicolumn{7}{|c|}{ Hypertension } \\
\hline No & 129 & 67 & 119 & 40 & $1.55(0.95-2.53)$ & 0.07 \\
\hline Yes & 94 & 45 & 135 & 41 & $1.58(0.93-2.68)$ & 0.07 \\
\hline \multicolumn{7}{|c|}{ Diabetes mellitus } \\
\hline No & 171 & 78 & 229 & 74 & $1.41(0.95-2.09)$ & 0.07 \\
\hline Yes & 52 & 34 & 25 & 7 & 2.34 (0.85-7.08) & 0.07 \\
\hline \multicolumn{7}{|c|}{ Tobacco smoking } \\
\hline Never & 129 & 60 & 165 & 52 & $1.48(0.93-2.34)$ & 0.08 \\
\hline Yes & 94 & 52 & 89 & 29 & $1.70(0.96-3.03)$ & 0.05 \\
\hline \multicolumn{7}{|c|}{ Alcohol drinking } \\
\hline Never & 113 & 57 & 147 & 49 & $1.51(0.94-2.45)$ & 0.07 \\
\hline Yes & 111 & 54 & 107 & 32 & $1.63(0.95-2.81)$ & 0.06 \\
\hline
\end{tabular}

\section{DISCUSSION}

In the present study, the roles of two important polymorphisms of the MMP3 rs3025058 and MMP9 rs3918242 in ischemic stroke risk in a sample of Chinese population were assessed. The results of this study revealed that the MMP9 rs3918242 polymorphism is associated with an increased risk of ischemic stroke, so that the CC genotype of MMP9 rs3918242 increased the risk of ischemic stroke in comparison with the TT genotype. However, no significant association was observed between MMP3 rs3025058 variant and ischemic stroke risk. Furthermore, subjects carrying the $\mathrm{TC}+\mathrm{CC}$ genotype interact with $\mathrm{BMI}$ in the development of ischemic stroke.

Several studies have reported a significant association between expression of MMP9 and the ischemic stroke risk (Nie et al., 2014; Zhang et al., 2015). Zhang et al. (2015) conducted a study with 222 Chinese patients with ischemic stroke, and reported that the CT+TT genotype of MMP9 rs3918242 was correlated with an increased risk of ischemic stroke. Our results are not consistent with a previous study performed in 396 Chinese patients with ischemic stroke, and they found that the TT genotype and T allele frequencies of MMP9 rs3918242 polymorphism were associated with increased risk of ischemic stroke (Nie et al., 2014). Other studies, however, reported no association between MMP9 rs3918242 polymorphism and ischemic stroke risk (Montaner et al., 2003; Manso et al., 2010; Szczudlik et al., 2010). Montaner et al. (2003) conducted a study in a Spanish population and found no association between MMP9 rs3918242 polymorphism and the development of stroke. In another study in a Polish population, Szczudlik et al. (2010) showed no significant association between the MMP9 rs3918242 polymorphism and increased risk of ischemic stroke. Since stroke is a complex disease and caused by many risk factors, MMP9 rs3918242 polymorphism could not be responsible for all the impacts for the development of ischemic stroke. Therefore, the discrepancies of these studies might be explained by the ethnic variations, differences in the source of patients and controls and sample size.

In the present study, the MMP9 rs3918242 polymorphism was shown to interact with higher BMI in the development of ischemic stroke. The MMP9 rs3918242 polymorphism has previously also been shown to be associated with high BMI-related diseases such as type 2 diabetes, coronary heart disease, and myocardial infarction (Ahluwalia et al., 2009; Wang et al., 2011; Li et al., 2013). There is a great need for further studies to confirm these findings reported here. 
There were some limitations to our study. First, control subjects are free of ischemic stroke by medical history, lack of examination by CT or MRI. Without confirmation of imaging examinations, some control subjects may have been affected by silent stroke, which may reduce the statistical power to find difference between groups. Second, some other genetic polymorphisms may contribute to the development of ischemic stroke, and have interaction with MMP-9 polymorphism, but our study did not consider other genes. Third, the study sample size was relatively small, which may limit the statistical power for the identification of differences between groups.

The findings of our study suggest that the MMP9 rs3918242 polymorphism plays a critical role in the pathogenesis of ischemic stroke, and that this gene polymorphism interacts with BMI in the risk of ischemic stroke. Our study provided new clinically information for impact of MMP3 and MMP9 gene polymorphisms on the susceptibility to stroke.

\section{Conflicts of interest}

The authors declare no conflict of interest.

\section{ACKNOWLEDGMENTS}

This study was funded by the Science and Technology Research Project of Health and Family Planning Commission in Henan Province (Grant \#201303105).

\section{REFERENCES}

Ahluwalia TS, Khullar M, Ahuja M, Kohli HS, et al. (2009). Common variants of inflammatory cytokine genes are associated with risk of nephropathy in type 2 diabetes among Asian Indians. PLoS One 4: e5168.

Chen Q, Jin M, Yang F, Zhu J, et al (2013). Matrix metalloproteinases: inflammatory regulators of cell behaviors in vascular formation and remodeling. Mediators Inflamm. 2013: 928315.

Fatar M, Stroick M, Steffens M, Senn E, et al. (2008). Single-nucleotide polymorphisms of MMP-2 gene in stroke subtypes. Cerebrovasc. Dis. 2008: 26: 113-119.

Galis ZS and Khatri JJ (2002). Matrix metalloproteinases in vascular remodeling and atherogenesis: the good, the bad, and the ugly. Circ. Res. 90: 251-262.

Goldstein LB, Bushnell CD, Adams RJ, Appel LJ, et al. (2011). Guidelines for the primary prevention of stroke: a guideline for healthcare professionals from the American Heart Association/American Stroke Association. Stroke 42: 517-584.

Kaplan RC, Smith NL, Zucker S, Heckbert SR, et al. (2008). Matrix metalloproteinase-3 (MMP3) and MMP9 genes and risk of myocardial infarction, ischemic stroke, and hemorrhagic stroke. Atherosclerosis 201: 130-137.

Katakami N, Takahara M, Kaneto H, Shimizu I, et al (2010). Accumulation of gene polymorphisms related to plaque disruption and thrombosis is associated with cerebral infarction in subjects with type 2 diabetes. Diabetes Care 33: 390-395.

Li J, Lu H, Tao F, Zhou H, et al. (2013). Meta-analysis of MMP9-562C/T and the risk of coronary heart disease. Cardiology 124: 53-59.

Manso H, Krug T, Sobral J, Albergaria I, et al. (2010). Variants of the Matrix Metalloproteinase-2 but not the Matrix Metalloproteinase-9 genes significantly influence functional outcome after stroke. BMC Med. Genet. 11: 40.

Moniche F, Montaner J, Gonzalez-Marcos JR, Carmona M, et al. (2014). Intra-arterial bone marrow mononuclear cell transplantation correlates with GM-CSF, PDGF-BB, and MMP-2 serum levels in stroke patients: results from a clinical trial. Cell Transplant. 1: S57-S64.

Montaner J, Fernández-Cadenas I, Molina CA, Monasterio J, et al. (2003). Safety profile of tissue plasminogen activator treatment among stroke patients carrying a common polymorphism (C-1562T) in the promoter region of the matrix metalloproteinase-9 gene. Stroke 34: 2851-2855.

Nie SW, Wang XF and Tang ZC (2014). Correlations between MMP-2/MMP-9 promoter polymorphisms and ischemic stroke. Int. J. Clin. Exp. Med. 7: 400-404.

Siefert SA and Sarkar R (2012). Matrix metalloproteinases in vascular physiology and disease. Vascular 20: 210-216. 
Szczudlik P and Borratyńska A (2010). Association between the -1562 C/T MMP-9 polymorphism and cerebrovascular disease in a Polish population. Neurol. Neurochir. Pol. 44: 350-357.

Wang L, Ma YT, Xie X, Yang YN, et al. (2011). Association of MMP9 gene -1562 C/T polymorphism with myocardial infarction in Uighur population of Xinjiang. Zhonghua Yi Xue Yi Chuan Xue Za Zhi 28: 180-184.

Zhang X, Cao X, Xu X, Li A, et al. (2015). Correlation between the -1562C/T polymorphism in the matrix metalloproteinase-9 gene and hemorrhagic transformation of ischemic stroke. Exp. Ther. Med. 9: 1043-1047. 